\title{
A Novel Clinical Intervention for Severe Childhood Depression and Anxiety
}

\author{
VICKY FLORY \\ Australian Catholic University
}

\begin{abstract}
A novel clinical intervention, Emotionally Attuned Parenting, was developed and trialed for severe childhood depression and anxiety. The intervention was designed to alleviate child psychopathology by improving quality of parenting. Parents of eleven children aged between 6 and 13 years who were outpatients in a public mental health service completed treatment. Parents received between 5 and 13 treatment sessions that aimed to increase parental empathy and improve emotional care of the child. $T$-test analyses revealed that the intervention was related to a significant reduction in psychiatric disorders, child-reported depression and anxiety, parenting stress, and a marginally significant reduction in child behaviour problems. Data available for five cases at 6 months follow-up indicated that gains were maintained. Implications of results for treatment of severe childhood psychiatric disorders and the role of parental empathy are explored.
\end{abstract}

\section{KEYWORDS}

childhood psychopathology, comorbidity, depression, parental empathy, treatment

TREATMENT APPROACHES for childhood psychiatric disorders have two major limitations: they do not address comorbidities, and they are not adequately informed by developmental issues.

The most severe cases of childhood psychopathology are characterized by psychiatric comorbidities and impairments in the parent-child relationship, social and academic functioning (Bernstein, 1991; Ialongo, Edelsohn, Werrhamer-Larsson, Crockett, \& Kellam, 1995; Manassis \& Menna, 1999; Puig-Antich et al., 1985). Comorbid psychiatric

VICKY FLORY is a Lecturer in the School of Psychology at Australian Catholic University, Melbourne, Australia. She is currently conducting research on the impact of parental empathy on child development and treatment of severe childhood psychopathology. She also has a private practice.

COntact: Australian Catholic University, Melbourne Campus (St Patrick's), 115 Victoria Parade, Fitzroy, VIC 3065, Australia. E-mail: v.flory@patrick.acu.edu.au 
disorders characterize the majority of clinically referred children (Kasius, Ferdinand, Berg, \& Verhulst, 1997) and are often related to poorer prognosis, for example, the presence of an externalizing disorder increases the average length of dysthymic disorder by 2 years (Kovacs, Obrosky, Gatsonis \& Richards, 1997). However, research has focused on disorder-specific treatments that are trialed using carefully selected cases in which exclusions apply for comorbid conditions or disadvantages, for example, intellectual difficulties (Barrett, Dadds, Rapee, \& Ryan, 1996; Spence, Donovan, \& BrechmanToussaint, 2000; Vostanis, Feehan, Grattan, \& Bickerton, 1996). Lack of research on children with comorbid psychiatric disorders means that the relevance of treatment trial results is not known. It can be argued that this group of children most urgently requires treatment, yet current research findings do not show what is suitable treatment.

Another key limitation is that treatments for child psychopathology are not sufficiently informed by developmental issues. For example, treatment for childhood major depressive disorder and dysthymic disorder typically involves downward extension of adult interventions, including cognitive-behaviour therapy and pharmacology (Goodyer, 2001). Researchers have acknowledged the need to address developmental issues in the treatment of children with psychiatric disorders - specifically, the child's dependence on their parents, the child's cognitive development and the extent to which parents, rather than the child, control the child's social context (Hammen, Rudolph, Weisz, Rao, \& Burge, 1999). Two steps are required for treatment to be guided by developmental issues: first the issues must be clearly identified, and then used to shape the form and content of treatment.

The role of parents in children's lives is a key developmental issue. Children are almost entirely dependent on parents for emotional support and so if parents are not supportive, children are emotionally isolated. Emotional isolation is contrary to mental health (Goodyer, Herbert, Tamplin, Secher, \& Pearson, 1997). Parents also affect child wellbeing through parent-child interactions. Extensive and robust evidence shows that punitive, abusive, harsh and unsupportive parenting is related to externalizing and internalizing behaviour problems (Puig-Antich et al., 1985) and increased child distress (Fabes, Leonard, Kupanoff, \& Martin, 2001). Psychiatric disorders are associated with parent-child relationships that have poor verbal and affective communication, tension between the parent and child, distance and a lack of warmth compared with normal controls (Flory, Vance, Birleson, \& Luk, 2002, Lizardi et al., 1995; Puig-Antich et al., 1985). Children's psychological well-being is also affected by parental cognitions about the child - attributions of hostility to the child are related to aggressive and non-compliant behaviour (Nix et al., 1999). Improving the quality of parental care, therefore, appears relevant to the treatment of childhood depression, and to childhood psychopathology more broadly.

\section{Novel clinical intervention}

A new treatment called Emotionally Attuned Parenting was designed to improve the parent-child relationship by increasing parental empathy towards the child. Empathy is a necessary precondition for parents to be able to meet their child's emotional needs. Given that depressive disorders are disorders of emotion, this is especially relevant to treatment. The Emotionally Attuned Parenting intervention was designed for depressive disorders with comorbid psychiatric disorders, both internalizing and externalizing.

Emotionally Attuned Parenting is based on my theory of parental empathy, which holds that parental cognitions facilitate or hinder parents' empathy towards their child. Empathy involves both a cognitive component - taking another person's perspective, and an affective component - other-oriented emotions such as concern about someone's 
distress (Davies, 1994). My theory outlines four cognitions that a parent may hold about a child that are pivotal in determining whether the parent will have empathy. Cognitions that hinder parental empathy are that the child is hostile, unreasonable, not genuine in demonstrated emotions and not emotionally dependent on parents. These cognitions are related to a specific child, therefore parents might have negative cognitions about one child, and positive cognitions about another child, and hence varying degrees of empathy towards their children. There is evidence that parenting cognitions and behaviours differ for different children within the one family (Bugental \& Cruscosa, 1989; Reiss et al., 1995).

The origin of negative parental cognitions about a child warrants further investigation. A range of factors may contribute including beliefs held prior to the child's birth, a resemblance between a child and a disliked relative, stress or adverse events, and the parent having received poor parental care themselves. Proximal events, such as negative evaluations of the child by relatives and friends, and the child's behaviour, may also serve to establish and reinforce negative parental cognitions about a specific child.

The cognition that 'the child is hostile' interferes with parental empathy because the parent interprets events with the premise that the child's motives are underpinned by malice. For example, a child starts crying and throwing a tantrum because a sibling has taken his favourite toy. A parent who believes their child is hostile is likely to interpret the child's behaviour as indicating 'he hates his sister and therefore doesn't want to share', 'his tantrum is an effort to manipulate the situation to get what he wants'. These negative interpretations focus the parent's mind on the child's behaviour rather than his feelings. From the child's point of view, he is upset because his sister has his toy and is so overwhelmed by his emotions that he tantrums and cries. However, the parent only sees the 'bad' behaviour, not the distressed emotions fuelling the behaviour. The parent feels angry or irritated and responds punitively or dismissively. The child does not have his emotional needs met - which in this case would be a soothing response to help him regain emotional equilibrium. Instead the child feels ignored or attacked by his parent, which leads to increased distress, and greater emotional (and behavioural) dysregulation.

Conversely, a parent who holds the cognition their child is benign would tend to interpret this situation as indicating that the child is finding it hard to share because he is a child, or maybe feeling sensitive this day. Parents who believe their child is benign are likely to generate explanations for their child's behaviour that assume the child's goodwill, for example, interpreting misbehaviour as stemming from negative feelings, having a 'bad day', or other causes that do not reflect poorly on the child's character.

The second cognition that hinders parental empathy is 'the child is unreasonable'. This puts a psychological distance between the parent and child (nobody sees themselves as unreasonable!) and the parent is less likely to think that the child is experiencing what they would, in similar circumstances. Parental empathy is stymied because the parent interprets events with the assumption that the child cannot be understood, as they are not 'reasonable'. The parent's focus is on the child's behaviour, rather than trying to understand the child's feelings. The cognition that the child is unreasonable arouses anger and punitive responses that do not meet the child's emotional needs.

Conversely, parents who believe their child is reasonable interpret the child's behaviour with the premise that from the child's point of view, their behaviour or feelings seem justified. The parent tries to understand their child's perspective and is likely to be concerned about their child's distress, and therefore motivated to help their child emotionally (e.g. by providing soothing or reassurance).

The third cognition 'the child is not genuine in demonstrated emotions' hinders 
empathy because it blinds parents to their child's emotional state. A child who is crying and screaming is obviously upset. However, parents may not interpret this as distress instead they may think she is trying to gain attention by pretending to be upset, or she is trying to manipulate her parents for her own ends, or that she is screaming and crying to get back at her parents by being aversive. Crying and screaming are salient examples, but of course children also show emotions by facial expressions, the extent of their quietness, physical movements and so forth. Parents may misconstrue any of these indicators of a child's emotions, and hence be perplexed by their child's 'bad' behaviour. When parents do not believe that the emotions their child is showing are genuine, they cannot empathize. A lack of empathy leads to an exclusive focus on the child's behaviour, and to a punitive or dismissive parenting response. This leaves the child without support and so their emotions and behaviour tend to escalate (e.g. louder screaming, more severe tantrums).

Conversely, parents who do believe their child is genuine in the emotions they demonstrate are able have an accurate understanding of the child's emotional state. This allows the parent to put the child's behaviour in context of their feelings and to empathize with the child's position.

The fourth cognition that hinders empathy is 'the child is not emotionally dependent on parents'. This makes parents unaware of the extent of the child's sensitivity and reliance on their parenting. This is likely to lead to a lack of parental motivation to try to understand their child's emotions or address them. Children are very emotionally dependent on their parents and need their parents' support to help them regulate their emotions. Parents who understand that they have a significant role to play are likely to be aware of their impact on their child's well-being.

Figure 1 outlines a non-empathic pathway that leads to increased child distress and greater psychopathology. Negative parental cognitions: that the child is hostile, unreasonable, not genuinely feeling the emotions they are displaying, and a lack of belief in the child's emotional dependence on parents, precludes an empathic interpretation of the child's behaviour. This leads to negative parental affect and negative parental behaviour, such as dismissing the child's emotion, or punitive responses, which do not meet the child's emotional needs, and thus increase the child's distress.

Figure 2 outlines an empathic pathway of parental care that results in the child's emotional needs being met, and thus reduces the child's distress and psychopathology. Positive parental cognitions: that the child is benign, reasonable, genuinely feeling the emotions they are displaying, and emotionally dependent on parents, facilitates an empathic interpretation of the child's behaviour. This leads to parental affect such as concern for the child, and to positive parental behaviour, for example, soothing or reassuring. Because the parent empathizes with the child, they are motivated to help the child and communicate this in their behaviour towards the child. This meets the child's emotional needs, and thus decreases the child's distress. Emotionally Attuned Parenting is designed to alter parental responses from the unempathic to the empathic pathway, and targets their cognitions, interpretations and behaviours towards the child.

Initial data were collected to examine the effectiveness of the intervention for children with severe depression and anxiety and comorbid psychiatric disorders. The method of recruitment is important in clinical research. Clinical cases are more severe on a number of indices compared with cases obtained through the community and by advertisement (Birmaher, Ryan, Williamson, Brent, \& Kaufman, 1996). This has implications for the generalization of treatment results. The aim was to trial the treatment for the most severe cases of childhood psychopathology, therefore, a clinical sample was used, 


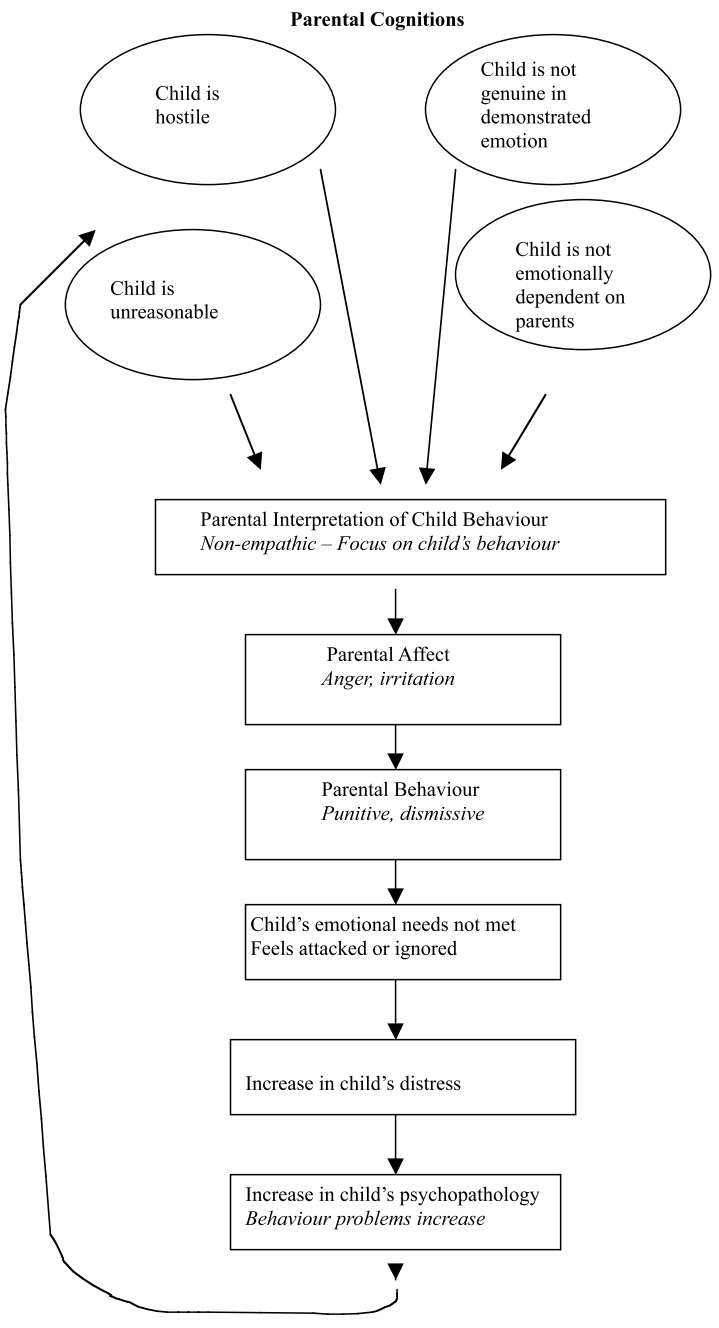

Figure I. Non-empathic pathway of parental care.

which contained children who had multiple psychiatric disorders and/or a history of non-responsiveness to treatment. It was expected that child psychopathology would reduce following the Emotionally Attuned Parenting intervention.

\section{Method}

\section{Participants}

Participants were outpatients in a public Child and Adolescent Mental Health Service. Cases were referred to the trial by clinicians on the basis of multiple psychiatric disorders, a history of non-responsiveness to treatment and/or a chronic depressive disorder. The only exclusion was a diagnosis of pervasive developmental disorder. 


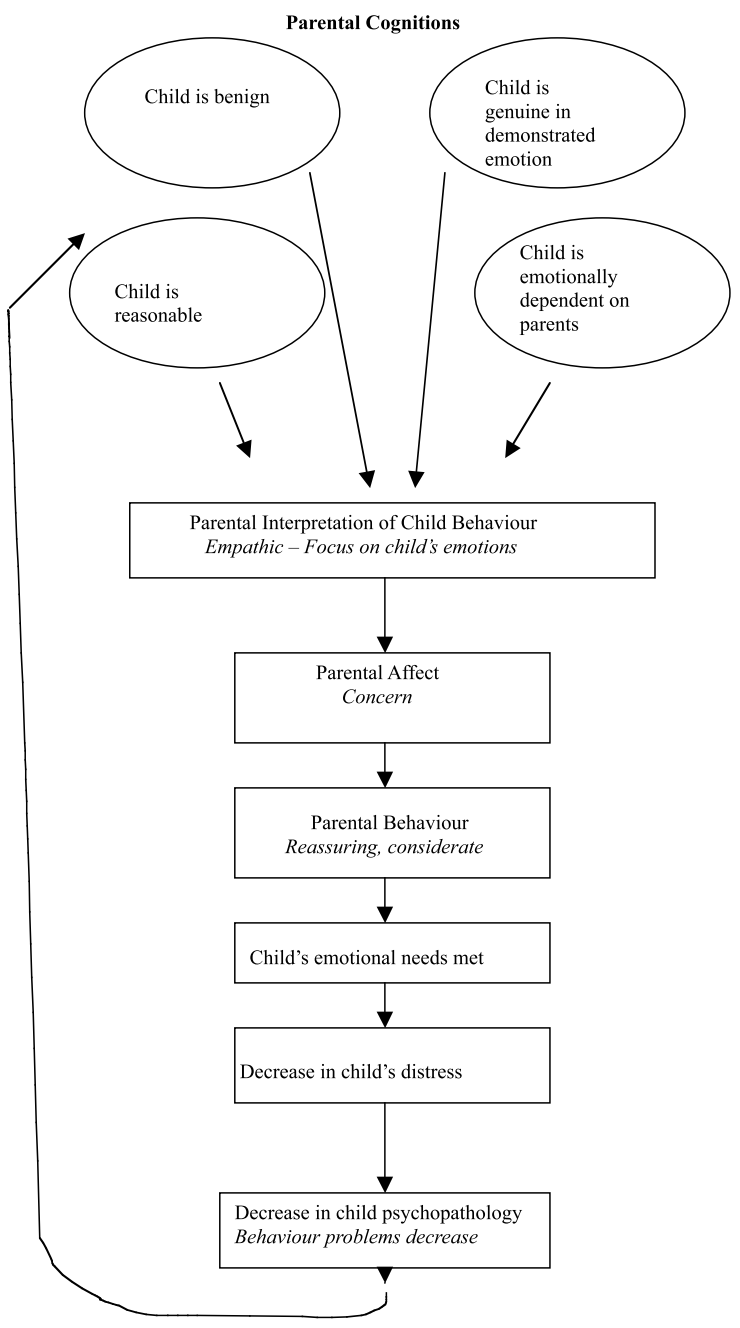

Figure 2. Empathic pathway of parental care.

Thirteen children aged 4-13 years and their parents were assessed and treated. Eleven (85\%) parents completed treatment; their children were aged 6-13 years $(M=9.36$, $\mathrm{SD}=2.29)$ and seven $(64 \%)$ were female. Intellectual function was in the normal range as measured by the Wechsler Intelligence Scale-III Full Scale IQ $(M=98.64, \mathrm{SD}=13.98$; range 77-123). Six children lived with both parents, three with mother and two with mother and stepfather.

\section{Materials}

The Anxiety Disorders Interview Schedule for Children (ADIS-C; Silverman \& Albano, 1996) was used as a basis to ascertain diagnoses according to DSM-IV criteria (American Psychiatric Association, 1994). Children and their parents were interviewed 
independently. For children aged 9 or above, diagnosis was determined by parent or child report. For children younger than 9 years, only parent report was used to determine diagnosis. The ADIS-C is a semi-structured interview that covers anxiety, mood and externalizing disorders. Each diagnosis is assigned a rating of impairment from 0 to 8 (not at all to very severe), scores of 4 and above indicate significant impairment. Good interrater (.84) and test-retest (.76) reliability rates have been reported (Silverman \& Eisen, 1992; Silverman \& Nelles, 1988).

The Revised Children's Manifest Anxiety Scale (RCMAS; Reynolds \& Richmond, 1978 ) is a 37 item self-report instrument for children aged 6 to 19 years. For each item, children respond whether the item describes them, 'yes' or 'no'. Four subscales are included: Physiological Anxiety, Worry/Oversensitivity, Social Concern/Concentration, and Lie. The first three subscales are summed to obtain the Total Anxiety score, which is reported as a percentile or T-score. A reliability coefficient of .82 has been reported (Reynolds \& Richmond, 1978).

The Children's Depression Scale (Lang \& Tisher, 1978) is a 66-item instrument used to measure children's depressive symptoms. The subscales include Affective Response, Social Problems, Self-Esteem, Preoccupation with Sickness and Death, Guilt and Miscellaneous Depression items. Children rate the extent to which each item describes them, from 1 (very wrong) to 5 (very right). Subscales are summed to form the Total Depression Score.

The Child Behaviour Checklist (Achenbach, 1991) is a 120-item instrument for children aged 4 to 18 years, used to obtain parental reports of behaviour problems. Parents report the extent to which each statement describes their child from 0 (not true) to 2 (very true). The Internalizing scale includes the withdrawn, somatic complaints and anxious/depressed subscales. The Externalizing scale includes the delinquent behaviour and aggressive behaviour subscales. The Total score is a composite of the Internalizing and Externalizing scales, and is converted to a T-score. Internal consistencies of .84 for the Internalizing scale and .90 for the Externalizing scale have been reported (Achenbach, 1991).

The Parenting Stress Index (Abidin, 1995) is a 120-item instrument used to measure self-reported parenting stress. It measures stress related to the Child domain, which includes subscales of Distractibility/Hyperactivity, Adaptability, Reinforces Parent, Demandingness, Mood and Acceptability. It also measures stress related to the Parent domain, including subscales of Competence, Isolation, Attachment, Health, Role Restriction, Depression and Spouse. Total Stress is computed by adding the Child and Parent domains. There is also a Life Stress scale. Parents respond to each item on a 5point scale (strongly agree to strongly disagree). Internal consistency for the Child and Parent domains, and the Total Stress has been reported at .90 or above (Abidin, 1995). Test-retest reliability coefficients have been reported at .82 for the Child domain, .71 for the Parent domain and .96 for Total stress across a 3-week interval (Burke, 1978).

The Beck Depression Inventory (Beck, 1996) is a 21-item instrument used to measure cognitive, affective and behavioural symptoms of depression in adults. Respondents indicate the extent to which they have experienced each symptom in the past 2 weeks, with scores from 0 to 3. Responses are summed, with levels of depression as follows, 0-13 minimal, 14-19 mild, 20-28 moderate and 29-36 severe. A test-retest reliability coefficient of .93 has been reported and there is evidence of convergent and discriminant validity (Beck, Steer, \& Garbin, 1988).

Wechsler Intelligence Scale for Children - III (WAIS-III; Wechsler, 1991), is a measure of children's intellectual function. It has Verbal and Performance subscales and a full scale IQ. A test-retest reliability coefficient of .90 for the full scale IQ has been 
reported. Concurrent performance on the WISC-III and the Wechsler Preschool and Primary Scale of Intelligence has a correlation of .85 (Wechsler, 1989) and .96 with the Wechsler Adult Intelligence Scale - Revised (Sandoval, Sassenrath, \& Penaloza, 1988).

Parental satisfaction with the intervention was measured using a questionnaire specifically designed for the intervention. The quantitative aspect involved an overall satisfaction item, ranging from 1 (not at all satisfied) to 10 (extremely satisfied).

\section{Procedure}

Prior to treatment, children and parents were interviewed separately and administered the Anxiety Disorders Interview Schedule for Children (Silverman \& Albano, 1996) by the author. Children completed the Revised Children's Manifest Anxiety Scale (Reynolds \& Richmond, 1978) and the Children's Depression Scale (Lang \& Tisher, 1978). Mothers completed the Child Behaviour Checklist (Achenbach, 1991), the Parenting Stress Index (Abidin, 1995) and the Beck Depression Inventory (Beck, 1996).

Treatment consisted of weekly or fortnightly sessions with the parent(s), depending on the parents' preference. Children did not receive any treatment during this time. One child was on stimulant medication for attention deficit hyperactivity disorder for approximately 10 months prior to commencing treatment, and his medication was not altered for the duration of treatment. The author provided the Emotionally Attuned Parenting intervention.

\section{Content of sessions}

Initial session Psycho-education was provided to parents about the disorders that the child had, including course, prognosis, key features of the disorder(s) and how these affect the child's thinking and behaviour. For example, depressive disorders are associated with low self-esteem and a propensity to focus on negative information. The implications of this for parenting were highlighted, for example, if the parent were positive half the time, and negative the other half, it can be expected that a depressed child would focus more on the negative.

The approach of the intervention was explained to parent(s) - that the aim was to alleviate child psychopathology by improving parent-child interactions. Specifically, that the focus would be to help them to understand their child's feelings, and to improve parent-child interactions. This was explained in terms of the pivotal role that parents play in their child's mental health, and the extent of the child's dependence and sensitivity to the parents' reactions to them. The need to increase positive and reduce negative interactions was discussed, and examples of both were listed on a white board, with parents contributing. The negative cycle of interactions between parent and child was discussed in three ways - difficulty of being positive when the child is not, that the child will change after the parent does, and that one key explanation for the child's negative behaviour is their psychiatric disorders. Also discussed was the importance of parents' cognitions about the child, that parents' interpretations of their child's behaviour influences how parents feel, and respond to the child, and therefore affect the child.

Sessions 2-13 (Total sessions ranged from 5 to 13) Subsequent sessions were conducted as follows - discussion of conflict times during the past week(s), or times that the child was misbehaving or distressed (e.g. crying or threatening suicide). Parental interpretations of these events were explored, the extent to which they were empathic, their feelings and behaviours towards the child, and the child's reaction. When negative parental cognitions were evident, for example, the child was displaying signs of distress, 
but the parent perceived that the child was being manipulative, the therapist helped the parent to identify their cognition and see the effect it had on their parenting response, and therefore, the negative impact on the child's feelings and behaviour. Techniques to alter cognitions included challenging, examining the evidence and analogies with adult feelings and behaviour. A similar process was undergone when examining parental responses. The effect of punitive responses on the child's feelings and behaviour was examined. The role that a child's emotions play in their behaviour was emphasized throughout the sessions.

Parenting sessions were aimed at increasing the parents' empathy for their child by raising awareness of their child's distress, challenging negative cognitions about their child, helping parents to recognize that their child's distress was causing their behaviour, and strategies for soothing and calming the child. In addition, the intervention aimed to increase awareness of the impact of parent-child interactions on the child and therefore to motivate parents to increase positive interactions and reduce negative interactions.

Treatment was finished by mutual agreement when the parent(s) reported the child's mood and behaviour had improved and/or the when the parents felt that they had a clear understanding of how to respond to their child.

All post-treatment and 6 months assessments (apart from one post-treatement assessment and one 6-month follow-up assessment) were performed by psychologists who did not administer the treatment. Post-treatment assessment consisted of the same measures as pre-treatment assessment, and also a therapy satisfaction questionnaire. Only five cases were due for 6-month follow-up while the author was still employed at the mental health service (and all these cases did participate in follow-up assessment). After the author changed her location of employment, there was no one available to organize follow-up assessment for the rest of the cases.

\section{Results}

\section{Length of treatment}

Thirteen cases commenced treatment and two dropped out, one case after one session, and the other case after five sessions. The remaining 11 cases attended between 5 and 13 sessions $(X=9.36, \mathrm{SD}=2.98)$. In $55 \%$ of cases only mothers attended treatment sessions, in the remaining cases, both parents attended. The variability in attendance was in part related to parents being able to terminate therapy when they felt they had the understanding and strategies in place to cope with their child in a positive manner. Examination of the relationship between attendance and outcome was performed using Pearson correlation, and this revealed there was not a statistically significant relationship between improvement on the CBCL and number of sessions attended, $r=.08$, $p=.39$. However, given the low sample size, it would be premature to conclude there was no dose effect.

\section{History of difficulties}

The duration of the child's difficulties ranged from 1.5 to 9 years $(X=5.32$ years, $\mathrm{SD}=2.06)$. Six $(55 \%)$ children had onset of difficulties within the first 3 years of life, and three $(27 \%)$ had problems since birth. Therefore, in nine $(82 \%)$ cases, difficulties emerged in the child's first 3 years of life.

\section{Diagnoses prior to treatment}

Nine children $(85 \%)$ had five or more psychiatric disorders. Table 1 shows patterns of comorbidity for each case. 
Table I. Patterns of comorbidity

\begin{tabular}{|c|c|}
\hline Case & Diagnoses \\
\hline 6-year-old boy & $\begin{array}{l}\text { Separation anxiety disorder, social phobia, dysthymic disorder, ADHD, conduct } \\
\text { disorder }\end{array}$ \\
\hline 7-year-old girl & $\begin{array}{l}\text { Generalized anxiety disorder, obsessive compulsive disorder, dysthymic disorder, } \\
\text { ADHD, oppositional defiant disorder }\end{array}$ \\
\hline 7-year-old girl & $\begin{array}{l}\text { Separation anxiety disorder, specific phobia, social phobia, generalized anxiety } \\
\text { disorder, obsessive-compulsive disorder, dysthymic disorder, ADHD, conduct } \\
\text { disorder }\end{array}$ \\
\hline 8-year-old girl & $\begin{array}{l}\text { Specific phobia, social phobia, panic disorder, generalized anxiety disorder, } \\
\text { obsessive-compulsive disorder, dysthymic disorder, major depressive disorder, } \\
\text { ADHD, conduct disorder }\end{array}$ \\
\hline 9-year-old girl & $\begin{array}{l}\text { Separation anxiety disorder, specific phobia, generalized anxiety disorder, } \\
\text { obsessive-compulsive disorder, oppositional defiant disorder }\end{array}$ \\
\hline 9-year-old boy & $\begin{array}{l}\text { Separation anxiety disorder, social phobia, generalized anxiety disorder, dysthymic } \\
\text { disorder, ADHD, conduct disorder }\end{array}$ \\
\hline I0-year-old girl & $\begin{array}{l}\text { Separation anxiety disorder, specific phobia, generalized anxiety disorder, } \\
\text { dysthymic disorder, oppositional defiant disorder }\end{array}$ \\
\hline 10-year-old boy & $\begin{array}{l}\text { Generalized anxiety disorder, dysthymic disorder, ADHD, oppositional defiant } \\
\text { disorder }\end{array}$ \\
\hline 12-year-old boy & Dysthymic disorder \\
\hline I2-year-old girl & $\begin{array}{l}\text { Separation anxiety disorder, specific phobia, generalized anxiety disorder, } \\
\text { dysthymic disorder, major depressive disorder }\end{array}$ \\
\hline I3-year-old girl & $\begin{array}{l}\text { Social phobia, panic disorder, generalized anxiety disorder, dysthymic disorder, } \\
\text { major depressive disorder }\end{array}$ \\
\hline
\end{tabular}

Table 2. Number (\%) of cases with psychiatric disorders pre treatment, post treatment and at 6 months follow-up

\begin{tabular}{lcll}
\hline & Pre Treatment & Post Treatment & 6 months $^{\text {' }}$ \\
\hline Dysthymic disorder & $11(100)$ & $5(45)$ & $0(0)$ \\
$\begin{array}{l}\text { Major depression } \\
\text { Anxiety disorders }\end{array}$ & $3(27)$ & $2(18)$ & $0(0)$ \\
$\begin{array}{l}\text { Attention deficit } \\
\text { hyperactivity disorder }\end{array}$ & $10(90)$ & $6(55)$ & $1(20)$ \\
$\begin{array}{l}\text { Conduct disorder or oppositional } \\
\text { defiant disorder }\end{array}$ & $6(55)$ & $5(45)$ & $2(40)$ \\
\end{tabular}

' Data available for only five cases (percentages in this column were based on the five cases, not the total sample).

As can be seen in Table 2, 11 (100\%) children had dysthymic disorder, and 10 (90\%) had comorbid anxiety disorders. The rates of specific anxiety disorders were as follows: nine $(82 \%)$ had generalized anxiety disorder, six $(55 \%)$ had separation anxiety disorder, five $(45 \%)$ had social phobia, five $(45 \%)$ had a specific phobia, four $(36 \%)$ had obsessive compulsive disorder and two (18\%) had panic disorder.

Conduct disorder was present in four (36\%) cases, and oppositional defiant disorder in five $(45 \%)$ cases. Rates of both disorders declined at post treatment, to two $(18 \%)$ and four $(36 \%)$ cases, respectively.

As can be seen in Table 3, the number of psychiatric disorders significantly declined post treatment, $t(10)=3.56, p=.005$. Because of limited numbers, 6-month follow-up rates were not analysed statistically, but figures are included for interest. 
Table 3. Mean number of psychiatric disorders per child

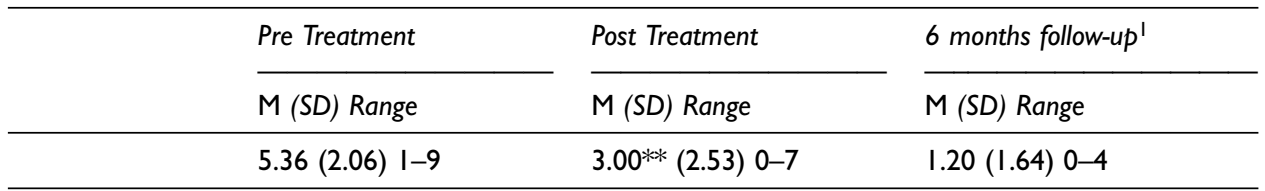

I Only five cases available for this time.

$* * p<.01$.

Table 4. Means and SD for outcome measures pre- and post treatment

\begin{tabular}{|c|c|c|c|c|c|c|}
\hline & \multicolumn{2}{|c|}{ Pre Treatment } & \multicolumn{2}{|c|}{ Post Treatment } & \multicolumn{2}{|c|}{6 months 1} \\
\hline & $M$ & $S D$ & M & SD & $M$ & $S D$ \\
\hline Child Behaviour Checklist & 72.73 & 13.52 & 68.45 & 14.09 & 58.40 & 9.42 \\
\hline \multicolumn{7}{|l|}{ Total T score } \\
\hline \multicolumn{7}{|l|}{ Revised Manifest Anxiety } \\
\hline Scale T score & 51.45 & 16.10 & 43.73 & 12.36 & 43.20 & 19.92 \\
\hline \multicolumn{7}{|l|}{ RCMAS subscales } \\
\hline Physiological & 10.36 & $3.4 \mathrm{I}$ & 8.64 & 2.84 & 9.20 & 3.96 \\
\hline Worry/oversensitivity & 9.64 & 4.27 & 8.09 & 2.47 & 7.00 & 5.10 \\
\hline Social Concerns & 10.00 & 4.69 & 9.73 & 3.20 & 8.40 & 4.56 \\
\hline Lie & 9.73 & 3.17 & 9.91 & 3.05 & 10.20 & 2.77 \\
\hline \multicolumn{7}{|l|}{ Children's Depression } \\
\hline Scale & 137.00 & 41.32 & 117.18 & 46.01 & 105.00 & 36.01 \\
\hline Parenting Stress Index & 259.10 & 43.06 & 241.10 & 39.55 & 223.20 & 31.58 \\
\hline \multicolumn{7}{|l|}{ Beck Depression Scale } \\
\hline Maternal & 5.70 & 5.23 & 3.20 & 3.16 & 6.00 & 5.34 \\
\hline
\end{tabular}

I Data for only five cases available, these were not analysed statistically.

McNemar's tests for significant change were conducted to ascertain rates of change for different diagnostic groups. Dysthymic disorder was the only diagnostic category that reduced significantly post treatment, $\chi^{2}(1)=4.16, p<.05$.

Table 4 shows means and SD for children's anxiety, depression and behaviour from parent and child report. Paired samples $t$-tests were performed comparing pre- and post intervention scores. Six-month follow-up results were not analysed statistically due to low numbers. There was a trend for a reduction in parent-reported child behaviour problems, $t(10)=1.89, p=.08$. Child-reported anxiety declined significantly, $t(10)=2.14$, $p=.05$, as did child-reported depressive symptoms, $t(10)=2.57, p=.02$. Examination of subscales in the Revised Children's Manifest Anxiety Scale revealed that only the physiological symptoms scale declined significantly, $t(10)=2.50, p=.03$. Maternalreported parenting stress lessened significantly after treatment, $t(9)=2.18, p=.05$. Maternal depressive symptoms were in the normal range prior to and after treatment, and did not change significantly, $t(9)=1.70, p=.12$.

Mothers were highly satisfied with the intervention as indicated by their response on a 10-point scale (not at all to extremely), $M=8.36, \mathrm{SD}=1.03$ (range 7-10). Parents were asked to specify what, if any, changes had occurred in their parenting as a result of the intervention. Parents indicated that they were more focused on their child's feelings, had a better understanding of their child's feelings and were responding more positively to their child. 


\section{Discussion}

This study investigated the use of Emotionally Attuned Parenting to treat severe childhood depression and anxiety with comorbid disorders. Treatment was related to a significant reduction in the number of psychiatric disorders and significant decreases in child-reported anxiety and depressive symptoms, and parenting stress. Child behaviour problems reduced marginally.

These improvements appear most promising given that the sample consisted of children with severe and chronic psychopathology. The average length of difficulties was 5 years, which for most of the children constituted more than half their life. All children had dysthymic disorder prior to treatment, which has a natural history of 4 years ( 6 years in the presence of a comorbid externalizing disorder). The significant reduction in dysthymic disorder is an important finding, given that Kovacs et al. (1997) found that treatment did not reduce the length of this disorder. Further improvement at 6-month follow-up was evident for the five cases for whom data are available, indicating gains were maintained.

Emotionally Attuned Parenting differs from other interventions in the mechanism it targets. Interventions for child psychopathology tend to take one of two approaches. First, to try to ameliorate the disorder by directly treating the child - for example, pharmacological interventions seek to alter behaviour and mood through their effect on brain chemistry. Cognitive interventions attempt to alter the child's thoughts and beliefs by cognitive restructuring. The second approach is to alter the responses the child receives from their environment - applying behavioural techniques such as negative consequences and positive reinforcement. While Emotionally Attuned Parenting is closer to the second approach as it deals directly with parents and their responses to the child, it is markedly different. First, it places children's emotional needs centre stage. It is based on the assumption that meeting children's emotional needs is a mechanism by which to alleviate childhood psychiatric disorders. It aims to improve the child's quality of life by improving the emotional care they receive. The theory of parental empathy outlined may have implications for models of developmental psychopathology. In particular, unmet emotional needs may be one pathway to childhood psychiatric disorders.

A lack of parental empathy may be a key factor in the development and maintenance of childhood psychopathology. Parental empathy may serve as a feedback mechanism by which parents gain information about their child's emotional state and needs. Parental empathy allows parents to perceive which events or interactions distress the child - and this is likely to motivate parents to provide appropriate responses, for example, reassurance and support. A lack of empathy precludes supportive parenting - which is critical for helping a child regain emotional equilibrium and for the child to acquire emotional regulation skills. Prolonged or frequent emotional dysregulation may develop into depressive and anxiety disorders.

Parental empathy is also relevant to externalizing disorders. Oppositional defiant disorder and conduct disorder are related to excessive anger and irritability. It is recognized that children with oppositional defiant disorder or conduct disorder do not see their behaviour as deviant, but as a reaction to punitive interactions and/or unreasonable demands from their parents (or others). Children with oppositional defiant disorder or conduct disorder often feel disliked, that no one listens to them and that their perspective is not considered. Therefore, there appears to be a strong emotional component to oppositional defiant disorder and conduct disorder. A lack of empathy means that parents do not understand their child's emotional state. Without this understanding, the child's behaviour may often seem aberrant and unreasonable. Such interpretations lead 
to harsh or dismissive parenting that does not meet the child's emotional needs. The child retaliates to what they consider unfair treatment and this further reinforces negative parental cognitions. Therefore, parental empathy may play a role in the emergence and maintenance of externalizing disorders.

Given this hypothesized link between parental empathy and child well-being, research data are needed on whether a lack of parental empathy is indeed a precursor to child psychopathology and also whether high levels of empathy lead to optimal mental and emotional health in children. Data are currently being collected in this domain. If evidence were to emerge that parental empathy is necessary for adequate emotional care it would have implications for primary prevention programmes. Emphasis on parental empathy in parent education programmes may be warranted.

A further service implication is that children may not need to be part of the formal therapeutic process in terms of receiving direct input from the therapist. Instead, improved emotional care may be sufficient for alleviation of their disorders. The child's 'therapy' may be most effectively delivered by helping their parents to provide highquality emotional care as the child requires it in daily life. This may be the case because children are emotionally dependent on their parents and second, their distress and behavioural problems emerge (to their full extent) in daily life, not in the therapist's office. Improved parental emotional care may have a more profound impact than formal therapy because the child receives soothing and support when they need it most, and from their parents - who ideally have the role of being their primary emotional support and nurturer.

The results indicate that it is possible to improve parents' emotional care of their child by explicitly addressing the issue. Parents reported very high satisfaction with the intervention and the completion rate of $85 \%$ was reasonable. They also reported gaining understanding of their child's emotional states and needs. Nine sessions was the average treatment length, indicating that significant improvements can be achieved in a relatively short time.

A limitation of the study was that the Parental Empathy Questionnaire (Flory, 2001) had not been developed at the time of data collection. Therefore, it is difficult to determine whether child psychopathology reduced as a result of increases in parental empathy. It is important to test the central assumption of the intervention - namely, that parental empathy is the critical ingredient in the therapy. In future trials of Emotionally Attuned Parenting, it will be important to measure parental empathy pre- and post treatment and also to examine if a lack of parental empathy predicts relapse of childhood psychopathology.

Mothers in this sample were in the normal range on depressive symptoms. In clinical samples, maternal psychopathology tends to be significantly higher than in the community, so the sample appears biased in this regard. It will be important to investigate whether parents with depression, anxiety or personality difficulties are able to improve the quality of emotional care they provide to their child.

As this was a pilot project, no control or comparison group was used. A randomized controlled trial is currently in preparation to examine how Emotionally Attuned Parenting intervention compares with a behavioural intervention. This trial will involve follow-up for at least a year to examine the extent to which improvements are maintained.

Overall, the intervention shows promise for treatment of severe child psychopathology and warrants further research. The Emotionally Attuned Parenting intervention recognizes that the quality of emotional care contributes significantly to children's psychological well-being. 


\section{References}

Abidin, R. (1995). The Parenting Stress Index. Lutz, FL: Psychological Assessment Resources.

Achenbach, T.M. (1991). Integrative guide for the 1991 CBCL/4-18, YSR and TRF Profiles. Burlington: University of Vermont.

American Psychiatric Association. (1994). Diagnostic and statistical manual of mental disorders (4th ed.). Washington, DC: American Psychiatric Press.

Barrett, P.M., Dadds, M.R., Rapee, R.M., \& Ryan, S.M. (1996). Family intervention for childhood anxiety: A controlled trial. Journal of Consulting and Clinical Psychology, 64, 333-342.

Beck, A.T. (1996). Beck Depression Inventory II. New York: Psychological Corporation.

Beck, A.T., Steer, R.A., \& Garbin, M.G. (1988). Psychometric properties of the Beck Depression Inventory: Twenty-five years of evaluation. Clinical Psychology Review, 8, 77-100.

Bernstein, G.A. (1991). Comorbidity and severity of anxiety and depressive disorders in a clinic sample. Journal of the American Academy of Child and Adolescent Psychiatry, 30, 43-50.

Birmaher, B., Ryan, N., Williamson, D., Brent, D., \& Kaufman, J. (1996). Childhood and adolescent depression: A review of the past 10 years. Part II. Journal of the American Academy of Child and Adolescent Psychiatry, 35, 1575-1583.

Bugental, D.B., \& Cruscosa, M. (1989). Perceived control over caregiving outcomes: Implications for child abuse. Developmental Psychology, 25, 532-539.

Burke, W.T. (1978). The development of a technique for assessing the stresses experience by parents of young children. Unpublished doctoral dissertation, University of Virginia, Charlottesville.

Davies, M.H. (1994). Empathy: A social psychological approach. Boulder, CO: Westview Press.

Fabes, R.A., Leonard, S.A., Kupanoff, K., \& Martin, C.L. (2001). Parental coping with children's negative emotions: Relations with children's emotional and social responding. Child Development, 72, 907-920.

Flory, V. (2001). Parental Empathy Questionnaire. Unpublished instrument. Available from author.

Flory, V., Vance, A.L.A., Birleson, P., \& Luk, E.S.L. (2002). Early onset dysthymic disorder in children and adolescents: Clinical implications and future directions. Child and Adolescent Mental Health, 7, 79-84.

Goodyer, I.M., Herbert, J., Tamplin, A., Secher, S.M., \& Pearson, J. (1997). Short-term outcome of major depression. II. Life events, family dysfunction, and friendship difficulties as predictors of persistent disorder. Journal of the American Academy of Child and Adolescent Psychiatry, 36, 474-480.

Goodyer, I.M. (2001). The depressed child and adolescent. London: Cambridge University Press.

Hammen, C., Rudolph, K., Weisz, J., Rao, U., \& Burge, D. (1999). The context of depression in clinic-referred youth: Neglected areas in treatment. Journal of the American Academy of Child and Adolescent Psychiatry, 38, 64-71.

Ialongo, N., Edelsohn, G., Werrhamer-Larsson, L., Crockett, L., \& Kellam, S. (1995). The significance of self-reported anxious symptoms in first grade children: Prediction to anxious symptoms and adaptive functioning in fifth grade. Journal of Child Psychology and Psychiatry, 36, 427-437.

Kasius, M.C., Ferdinand, R.F., Berg, H., \& Verhulst, F.C. (1997). Associations between different diagnostic approaches to child and adolescent psychopathology. Journal of Child Psychology and Psychiatry, 38, 625-632. 
Kovacs, M., Obrosky, D.S., Gatsonis, C., \& Richards, C. (1997). First episode major depressive and dysthymic disorder in childhood: Clinical recovery and sociodemographic factors in recovery. Journal of the American Academy of Child and Adolescent Psychiatry, $36,777-784$.

Lang, M., \& Tisher, M. (1978). Children's Depression Scale: Research edition. Melbourne: Australian Council for Educational Research.

Lizardi, H., Klein, D.N., Ouimette, P.C., Riso, L.R., Anderson, R.L., \& Donaldson, S.K. (1995). Reports of the childhood home environment in early-onset dysthymia and episodic major depression. Journal of Abnormal Psychology, 104, 132-139.

Manassis, K., \& Menna, R. (1999). Depression in anxious children: possible factors in comorbidity. Depression and Anxiety, 10, 18-24.

Nix, R.L., Pinderhughes, E.E., Dodge, K.A., Bates, J.E., Pettit, G.S., \& McFadyen-Ketchum, S.A. (1999). The relation between mothers' hostile attribution tendencies and children's externalising behaviour problems: The mediating role of mothers' harsh discipline practices. Child Development, 70, 896-909.

Puig-Antich, J., Lukens, E., Davies, M., Goetz, D., Brennan-Quattrock, J., \& Todak, G. (1985). Psychosocial functioning in prepubertal major depressive disorders. I.

Interpersonal relationships during the depressive episode. Archives of General Psychiatry, 42, 500-507.

Reiss, D., Hetherington, E.M., Plomin, R., Howe, G.W., Simmens, S.J., Henderson, S.H., O'Connor, T.J., Bussell, D.A., Anderson, E.R., \& Law, T. (1995). Genetic questions for environmental studies. Archives of General Psychiatry, 52, 925-936.

Reynolds, C.R., \& Richmond, O.B. (1978). What I think and feel: A revised measure of children's manifest anxiety. Journal of Abnormal Child Psychology, 6, 271-280.

Reynolds, C.R., \& Richmond, O.B. (1978). Revised Children's Manifest Anxiety Scale. Los Angeles, CA: Western Psychological Services.

Sandoval, J., Sassenrath, J., \& Penaloza, M. (1988). Similarity of WISC-R and WAIS-R scores at age 16. Psychology in the Schools, 25, 373-379.

Silverman, W.K., \& Albano, A.M. (1996). The Anxiety Disorders Interview Schedule for Children. (DSM-IV). San Antonio, TX: Psychological Corporation.

Silverman, W.K., \& Eisen, A.R. (1992). Age differences in the reliability of parent and child reports of child anxious symptomatology using a structured interview. Journal of the American Academy of Child and Adolescent Psychiatry, 31, 117-124.

Silverman, W.K., \& Nelles, W.B. (1988). The Anxiety Disorders Interview Schedule for Children. Journal of the American Academy of Child and Adolescent Psychiatry, 27, 772-778.

Spence, S.H., Donovan, C., \& Brechman-Toussaint, M. (2000). The treatment of childhood social phobia: The effectiveness of a social skills training-based, cognitive-behavioural intervention, with and without parental involvement. Journal of Child Psychology and Psychiatry, 41, 713-726.

Vostanis, P., Feehan, C., Grattan E., \& Bickerton, W. (1996). Treatment for children and adolescents with depression: Lessons from a controlled trial. Journal of Child Psychology and Psychiatry, 1, 199-212.

Wechsler, D. (1989). Manual for the Wechsler Preschool and Primary Scale of IntelligenceRevised. San Antonio, TX: The Psychological Corporation.

Wechsler, D. (1991). Wechsler Intelligence Scale for Children - III. San Antonio, TX: The Psychological Corporation. 